\title{
The influence of initial conditions and open boundary conditions on shelf circulation in a 3D ocean-shelf model of the North East Atlantic
}

\author{
S.L. Wakelin, J.T. Holt and R. Proctor \\ Proudman Oceanographic Laboratory, Joseph Proudman Building, 6 Brownlow Street, \\ Liverpool, L3 5DA
}

Ocean Dynamics (2009) 59:67-81

DOI: $10.1007 / \mathrm{s} 10236-008-0164-3$

\begin{abstract}
Data from climatology (World Ocean Atlas) and two large scale operational ocean models (Forecasting Ocean Assimilation Model - FOAM, UK Met. Office) and the Navy Coastal Ocean Model - NCOM, US Naval Research Laboratory) are used to give initial and open boundary conditions for a northeast Atlantic implementation of the Proudman Oceanographic Laboratory Coastal Ocean Model System (POLCOMS). We study the effects of using the different datasets on the temperature fields and the circulation.

On the continental shelf, comparisons of POLCOMS output with AVHRR sea surface temperature data suggest that the effect of using different ocean model initial and boundary conditions is small and that, after 15 months of model time, the impact of the different initial conditions is negligible. Stronger evidence of influence is seen in the deeper oceanic regions of the domain. Volume fluxes through sections governing flow into and out of the North Sea, through the Irish Sea and along the shelf edge show that the impact of the different boundary conditions is small on the shelf but significant elsewhere. These results are contrasted with the use of climatology to assess the value of these Global Ocean Data Assimilation Experiment (GODAE) ocean model products.
\end{abstract}

\section{Introduction}

By definition, regional ocean models do not cover the whole globe and, in many cases, have open boundaries in deep water. In order to include the influence of large scale oceanic circulation, information on ocean dynamics and water properties outside the model area must be provided to the model at the boundaries. These external data might be taken from observations (often climatological) or from numerical models covering larger areas at reduced resolution. Data from deep ocean models have the advantage of generally higher spatial and temporal resolutions over larger areas and longer time periods than is possible with observations. Also, as is now common practice, the available observations are blended into the ocean model solution through data assimilation. Ocean model data also provide a consistent dataset with the pressure (sea surface and thermohaline structure) and currents in dynamical balance. The higher spatial resolution and more homogeneous coverage also make deep ocean models a good source of initial conditions for regional models. Unless the same numerical model is used for the regional model and the model providing the boundary condition, there may, however, be difficulties caused by differences in the physics of the two models.

The northeast Atlantic is a complex region with water depths ranging from more than $5500 \mathrm{~m}$ to the west of Spain to less than 150m over large areas of the northwest Europe continental 
shelf (Fig. 1). The region is affected by large-scale currents such as the Gulf Stream, the slope current that extends along much of the edge of the continental shelf, the intricate flows and overflows of pathways between the Atlantic Ocean and the Nordic seas and the predominantly anti-clockwise motion in the North Sea. Of particular importance to oceanshelf exchanges, the slope current is a continuous and persistent flow along the edge of the continental shelf from south of Porcupine Bank to the Faeroe-Shetland Channel, with transports $\sim 1-2 \mathrm{~Sv}\left(1 \mathrm{~Sv}=10^{6} \mathrm{~m}^{3} \mathrm{~s}^{-1}\right)$ in the Rockall Channel and $\sim 4-7 \mathrm{~Sv}$ in the FaeroeShetland Channel (Huthnance and Gould, 1989).

The Proudman Oceanographic Laboratory Coastal Ocean Model System (POLCOMS) is a three-dimensional baroclinic B-grid model described by Holt and James (2001) and Proctor and James (1996). It is a primitive equation finite difference model in spherical polar scoordinates. It has been used and validated over a wide range of scales (resolutions $\sim 1.8$ to $\sim 25 \mathrm{~km}$ ) and areas (Holt and James, 2001; Holt and James, 2006; Holt and Proctor 2003; Holt et al. 2005). POLCOMS has been developed to model baroclinic processes over a range of environments from shallow shelf regions, across the shelf slope and into the deep ocean and is a suitable tool for modelling the challenging environment of the northeast Atlantic.

Here we use published climatologies and data from two different operational ocean models as open boundary conditions for a northeast Atlantic implementation of POLCOMS. The focus of this work is on the affect that the different boundary datasets have on the circulation on the continental shelf. Specifically, we examine how sensitive the modelled circulation and the associated temperature field are to the open boundary condition relative to the model being used.

\section{The model}

The POLCOMS model is applied to the northeast Atlantic Ocean (the "Atlantic Margin") using essentially the formulation described by Holt and James (2001). The principal change to the model is the addition of horizontal diffusion/viscosity to the velocity, temperature and salinity fields in order to improve stability in deep water. For the horizontal diffusion calculation, the physics fields are interpolated onto z-levels and multiplied by a depthdependent diffusion coefficient $\left(\mathrm{A}_{\mathrm{H}}=0\right.$ for $\mathrm{H}<200 \mathrm{~m}, \mathrm{~A}_{\mathrm{H}}=0.2 \mathrm{Hm}^{2} \mathrm{~s}^{-1}$ for $200 \mathrm{~m}<\mathrm{H}<$ $3000 \mathrm{~m}, \mathrm{~A}_{\mathrm{H}}=600 \mathrm{~m}^{2} \mathrm{~s}^{-1}$ for $\left.\mathrm{H}>3000 \mathrm{~m}\right)$.

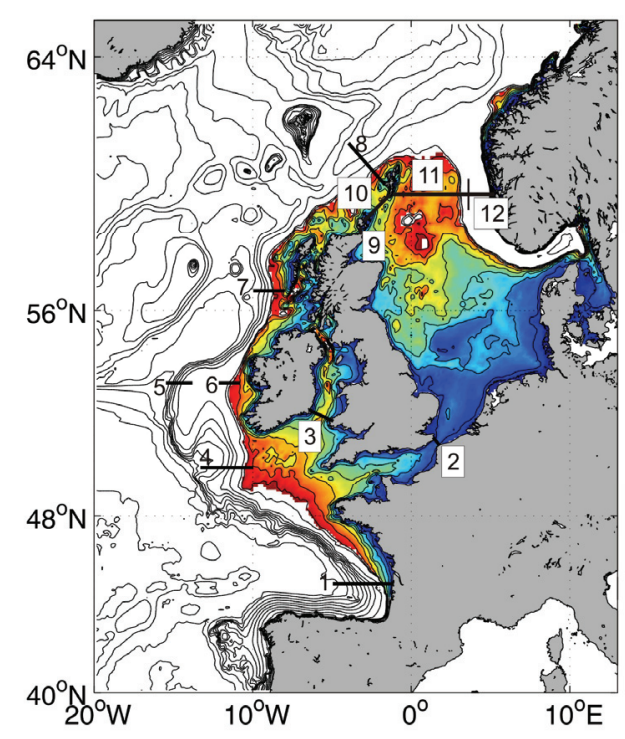

Fig. 1 Depth contours of the Atlantic Margin model. Contour intervals are $20 \mathrm{~m}$ for $0-160 \mathrm{~m}$ and $500 \mathrm{~m}$ for $500-5500 \mathrm{~m}$. The coloured region is the continental shelf with depths $<150 \mathrm{~m}$. The thick black lines and corresponding labels denote the locations of sections referred to in the text 
The Atlantic Margin Model (AMM) domain (Fig. 1) extends from the deep ocean to the coast from $40^{\circ} \mathrm{N}$ to $65^{\circ} \mathrm{N}$ and $20^{\circ} \mathrm{W}$ to $13^{\circ} \mathrm{E}$. The grid spacing is $1 / 9^{\circ}$ latitude by $1 / 6^{\circ}$ longitude $(\sim 12 \mathrm{~km}$ resolution) with $N=34$ levels in the vertical.

The vertical levels are in s-coordinates (modified $\sigma$-coordinates) to allow increased resolution near the surface and bed in deeper water. Following Song and Haidvogel (1994) and Holt and James (2001), $\sigma$-levels are defined by

$$
\sigma_{k}=S_{k}+\frac{h_{i, j}-h_{c}}{h_{i, j}}\left[C\left(S_{k}\right)-S_{k}\right], \text { for } h_{i, j}>h_{c}, \text { and } \sigma_{k}=S_{k}, \text { for } h_{i, j} \leq h_{c},
$$

where the $S_{k}$ are $N-1$ evenly spaced levels between $\sigma=-1$ and $\sigma=0, h_{c}=150 \mathrm{~m}$ is a critical depth and $h_{i, j}$ is the undisturbed water depth at point $(i, j)$. The function $\mathrm{C}\left(S_{k}\right)$ is defined by

$$
C\left(S_{k}\right)=(1-B) \frac{\sinh \left(\theta S_{k}\right)}{\sinh \theta}+B \frac{\tanh \left(\theta\left[S_{k}+0.5\right]\right)-\tanh (0.5 \theta)}{2 \tanh (0.5 \theta)},
$$

where $\theta=6$ and $B=0.8$. State variables are defined at points midway between the $\sigma_{k}$ levels at $0.5\left(\sigma_{k}+\sigma_{k+1}\right)$ for $k=1,2, \ldots, N-2$. Additionally, to simplify the calculations at the boundaries, position $k=0$ is defined at half a level below the sea bed and $k=N-1$ is defined at half a level above the sea surface.

\subsection{Bathymetry}

Bathymetry was obtained from the British Oceanographic Data Centre (P. Weatherall, personal communication, 1999). The bathymetry data were smoothed to remove some roughness in the deeper regions, which helps to reduce unstable eddies in the model, and at the western boundary near $55^{\circ} \mathrm{N}$ to help prevent eddies from becoming trapped on the boundary.

In $\sigma$-coordinate models, the calculation of the horizontal pressure gradient term traditionally involves estimating pressure gradients along the $\sigma$-levels and then correcting for the slope of the coordinate. These methods are prone to significant and well-known errors (e.g. Haney, 1991, Mellor et al., 1994) and, to overcome this problem, POLCOMS uses a method of estimating the horizontal pressure gradient term (Holt and James, 2001) by interpolating onto z-levels. However, in addition to using improved algorithms to reduce pressure gradient errors, some bathymetric smoothing is still needed to ensure realistic simulations using terrain-following coordinate systems in regions of large depth variations (Haidvogel et al., $2000)$. In the Atlantic Margin domain, the relatively coarse model resolution $(12 \mathrm{~km})$ and steep bathymetry combine to give depth changes exceeding $1800 \mathrm{~m}$ between grid points at the edge of the northwest European Continental Shelf to the west of France and 3600m off the coast of northern Spain. Some additional smoothing of the bathymetry is essential in these areas.

The model bathymetry was smoothed to reduce the maximum depth difference between adjacent grid points. Great care was taken during the smoothing process not to disrupt deep water pathways to the northwest of the UK and around the Faeroe Islands and smoothing was kept to the minimum which allowed a realistic slope current to develop. The smoothing was carried out by searching for points $(i, j)$ where in the surrounding 13 by 13 point box $(i-6: i+6$, $j-6: j+6$ ) depths extended from less than $200 \mathrm{~m}$ to greater than $800 \mathrm{~m}$. At such points, the bathymetry was averaged over 3 by 3 points along most of the edge of the continental shelf and over 9 by 9 points for the steepest section along the Spanish coast and up to $45^{\circ} \mathrm{N}$. To 
preserve the width of the continental shelf, no smoothing was done at points where the original depth was less than $100 \mathrm{~m}$. At the end of the smoothing process, the maximum depth difference between adjacent points was around $1600 \mathrm{~m}$ off the coast of northern Spain and $1300 \mathrm{~m}$ elsewhere along the continental slope.

The original steep bathymetry affected results in the AMM by preventing the slope current, observed to flow along the edge of the continental shelf, from forming; the revised bathymetry allows a slope current in good agreement with Huthnance and Gould (1989) and Souza et al (2000).

\subsection{Initial and boundary conditions}

The model is forced by mean sea level pressure, $10 \mathrm{~m}$ winds, air temperature, relative humidity and cloud cover from ECMWF operational analyses. All data are available 6-hourly, except for the clouds which are daily. Freshwater discharges from 279 European rivers (Young and Holt, 2007) are also included along with inflow from the Baltic. Tides are incorporated by using elevation and current boundary data of 15 tidal constituents from a twodimensional 30km-resolution model of the northeast Atlantic (Flather, 1981) and by including the equilibrium tide. Two sets of sub-tidal boundary conditions of barotropic currents and sea surface elevation are used, taken from two different operational models covering the North Atlantic. The total (tide + density component) current and elevation data are used in a flux/radiation boundary condition. The same operational models provide temperature and salinity data around the AMM boundary, interpolated on to the AMM s-levels. The modelled temperature and salinity are relaxed to the boundary data in a four-gridpoint-wide region around the model boundaries. Climatological temperature and salinity are also used to attempt to quantify the merits of model data over climate data in providing boundary conditions for regional models.

The two operational models used to supply boundary conditions to the AMM are the Forecasting Ocean Assimilation Model (FOAM, UK Met. Office, Bell et al., 2000) and the Navy Coastal Ocean Model (NCOM, US Naval Research Laboratory, Barron et al., 2006). The FOAM initial conditions are for $1^{\text {st }}$ January 1998 and boundary data are available every six hours until the end of 2003. The FOAM dataset is a combination of three FOAM runs with changes in forcing, parameters assimilated and/or model developments at April 2000 and November 2003. The NCOM initial conditions are for $1^{\text {st }}$ April 2001 and the boundary data are available daily until $15^{\text {th }}$ December 2001 and thereafter six-hourly until the end of 2003 . Climate temperature and salinity data were taken from the World Ocean Atlas 2005 (WOA05) database (Antonov et al., 2006 and Locarnini et al., 2006). The climate data consist of 12 monthly-mean temperature and salinity fields; initial fields are calculated for $1^{\text {st }}$ January 1998 by averaging the January and December means.

The FOAM model is based on the Bryan-Cox model (Bryan, 1969; Cox, 1984) with 1/3 ${ }^{\circ}$ horizontal resolution and $20 \mathrm{z}$-levels in the vertical and includes assimilation of observed temperature and sea level. The NCOM model is based on the Princeton Ocean Model (POM, Blumberg and Mellor, 1987) with $\sim 1 / 8^{\circ}$ horizontal resolution in mid-latitudes and 40 vertical levels (19 $\sigma$-levels near the surface with the remainder being z-levels). NCOM assimilates temperature and salinity observations.

Examples of the boundary data for 2002 are given in Fig. 2. During 2002, the sea surface temperature fields averaged over each boundary show close agreement between FOAM and 
$\mathrm{NCOM}$ with the main difference being that the FOAM data are $\sim 1{ }^{\circ} \mathrm{C}$ lower than the NCOM data at the northern boundary during the last four months of the year. The spatial averages along the western and southern boundaries are also in close agreement with the WOA05 data but the climatological summer temperatures along the northern boundary are several degrees cooler than the FOAM and NCOM data. The time-averaged plots show similar spatial patterns in the data with maximum differences between the datasets of $3^{\circ} \mathrm{C}$, occurring at the northern boundary at $\sim 11^{\circ} \mathrm{W}$ where the FOAM data is too warm compared to NCOM and WOA05. There is fair agreement between the salinity data sets with the climatological values generally higher than those of the two models but with similar spatial and temporal behaviour. The time-averaged elevations are offset by $\sim 0.25 \mathrm{~m}$ with FOAM elevations greater than NCOM. The FOAM data have an average north-south elevation difference of $0.32 \mathrm{~m}$ while the value for NCOM is $0.25 \mathrm{~m}$. At the northern boundary, both FOAM and NCOM data feature a coherent northwards-flowing current along the Norwegian coast and a southwards-flowing current at the coast of Iceland. The situation on the other boundaries is more complex and there are large differences between the two data sets with the NCOM currents generally larger and more variable than those of FOAM. The time variation of the spatial means shows a high degree of coherence, especially at the northern boundary.

The Atlantic Margin model was run from rest four times using the combination of initial and boundary conditions detailed in table 1 . The end date for all runs was $31^{\text {st }}$ December 2003, meaning that the AMM-climate and AMM-FOAM runs are for 72 months and the two NCOM-forced runs for 33 months.
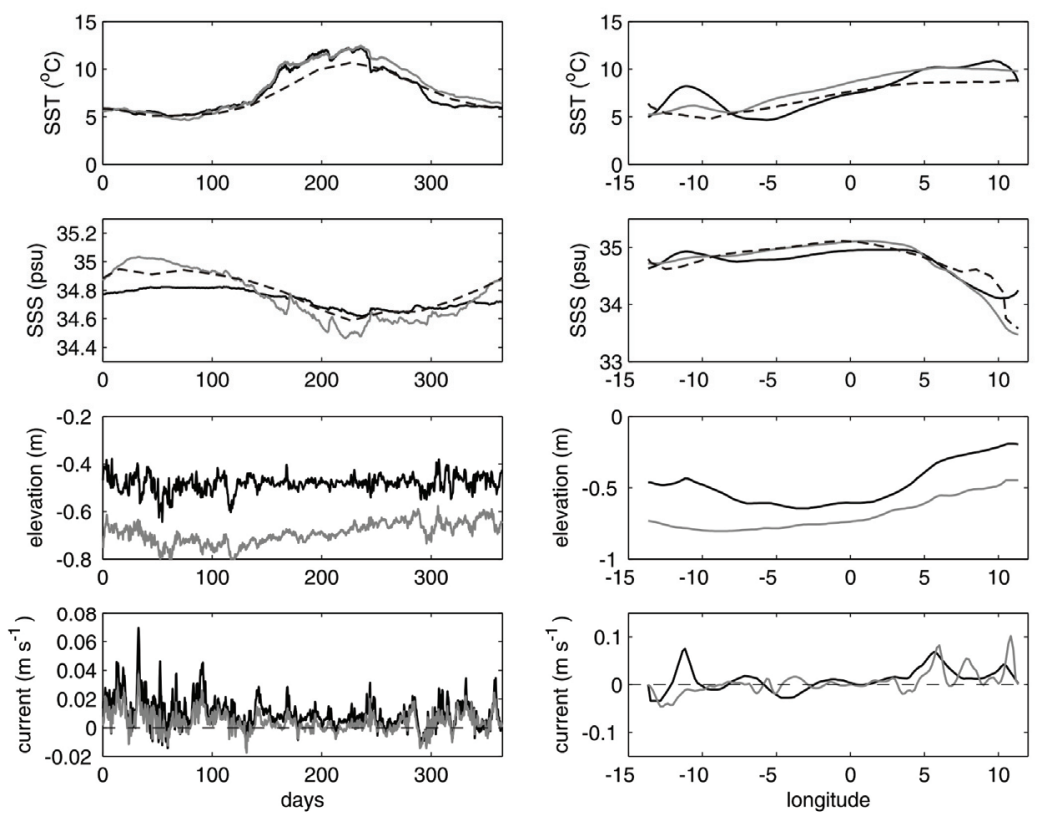

Fig. 2a Boundary data of sea surface temperature (SST), sea surface salinity (SSS), elevation and barotropic current normal to the boundary at the northern boundary of the AMM. The left-hand column shows the variation with time for 2002 of the spatial average along that boundary while the right-hand column shows the variation of the 2002 time-mean over the length of the boundary. The FOAM data are the black solid line, the NCOM data the grey solid line and, for the temperature and salinity only, the climatology from Word Ocean Atlas 2005 is the black dashed line 

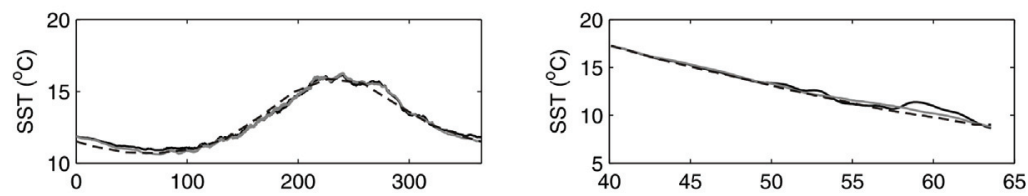

Fig. 2b As for Fig. 2a, but for the western boundary of the Atlantic Margin Model
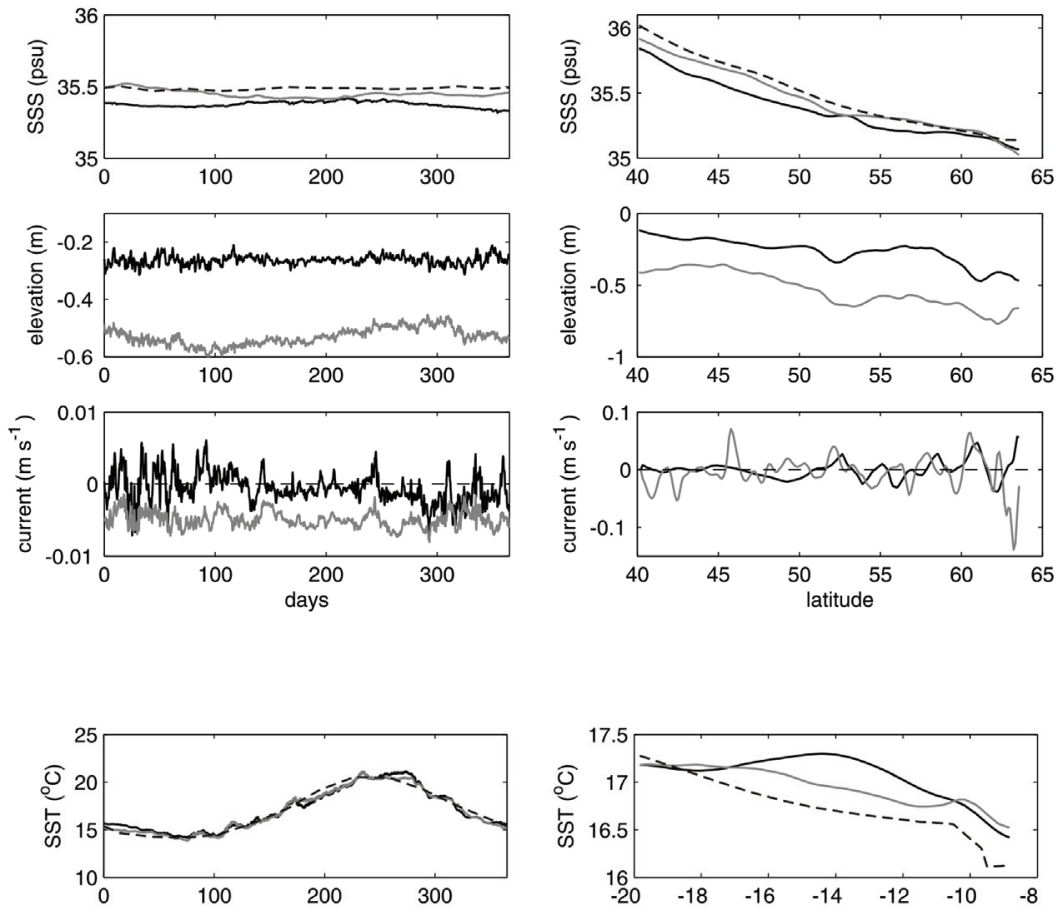

Fig. 2c As for Fig. 2a, but for the southern boundary of the Atlantic Margin Model
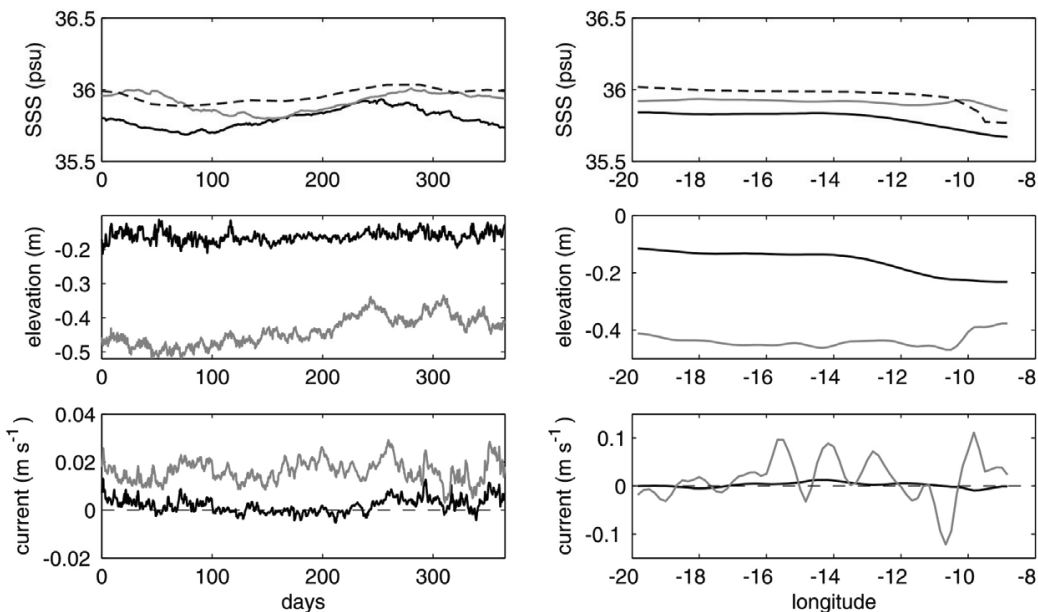

\begin{tabular}{|l|l|l|l|l|l|}
\hline $\begin{array}{l}\text { exper- } \\
\text { iment }\end{array}$ & name & $\begin{array}{l}\text { initial } \\
\text { temperature } \\
\text { and salinity }\end{array}$ & $\begin{array}{l}\text { boundary } \\
\text { temperature } \\
\text { and salinity }\end{array}$ & $\begin{array}{l}\text { boundary } \\
\text { elevation } \\
\text { and current }\end{array}$ & start date \\
\hline E1 & AMM-FOAM & FOAM & FOAM & FOAM & $1^{\text {st } J a n u a r y ~ 1998 ~}$ \\
\hline E2 & AMM-climate & WOA05 & WOA05 & FOAM & $1^{\text {st }}$ January 1998 \\
\hline E3 & AMM-NCOM & NCOM & NCOM & NCOM & $1^{\text {st }}$ April 2001 \\
\hline E4 & AMM-NCOM(FIC) & from run E1 & NCOM & NCOM & $1^{\text {st April } 2001}$ \\
\hline
\end{tabular}

Table 1 Descriptions of the four model experiments 


\section{Results}

\subsection{Temperature fields}

To assess the accuracy of the model's sea surface temperature and the sensitivity to the boundary and initial condition, the model results are compared to $9 \mathrm{~km}$ AVHRR data from January 1998 to June 2003. For each time, the observations are interpolated onto the model grid and the mean and RMS differences to the corresponding model value calculated (Fig. 3). Errors calculated over the whole domain are generally greater than those calculated only over the shelf and are larger in summer than in winter. By May 2001, the model is consistently underestimating the temperature by an average of about $0.5^{\circ} \mathrm{C}$ on the shelf and $0.5-1.5^{\circ} \mathrm{C}$ over the whole domain. The main source of the bias is likely to stem from the vertical mixing and surface heat flux equations used. The RMS errors are $\sim 0.8^{\circ} \mathrm{C}$ on the shelf and $\sim 1.0^{\circ} \mathrm{C}$ over the whole domain. The largest RMS errors over the whole domain are for the run using FOAM boundary data. After 15 months, the two runs with NCOM boundary conditions have similar errors showing that the affect of the initial condition has diminished. By the same time, the errors of all four model runs are almost identical when calculated over the shelf area only indicating that, once the affect of the initial condition has reduced, the sea surface temperatures over the shelf area depend more on the model properties and local meteorological forcing than on the boundary forcing.

There is evidence of drift in the model sea surface temperatures with the model becoming increasingly too cold compared to AVHRR (Fig. 3). The AMM-FOAM and AMM-climate runs show two distinct time periods. During January 1998 to November 1999 the models have mean errors fluctuating around zero; a change occurs during 2000 and, from 2001 onwards, the model progressively underestimates the surface temperature. Over the whole domain, the underestimation of temperature for AMM-FOAM increases by $0.31^{\circ} \mathrm{C}$ year ${ }^{-1}$ and for AMMclimate by $0.18^{\circ} \mathrm{C}_{\text {year }}{ }^{-1}$, compared to AVHRR data. The trends over the shelf are $0.16^{\circ} \mathrm{C}$ year $^{-1}$ (AMM-FOAM) and $0.08^{\circ} \mathrm{C}$ year $^{-1}$ (AMM-climate). The larger drifts for the domain which includes the deeper water are probably a consequence of lower resolution near the surface in AMM. From January 2002 onwards, the underestimation of surface temperature tends to improve over the shelf region in all model runs.

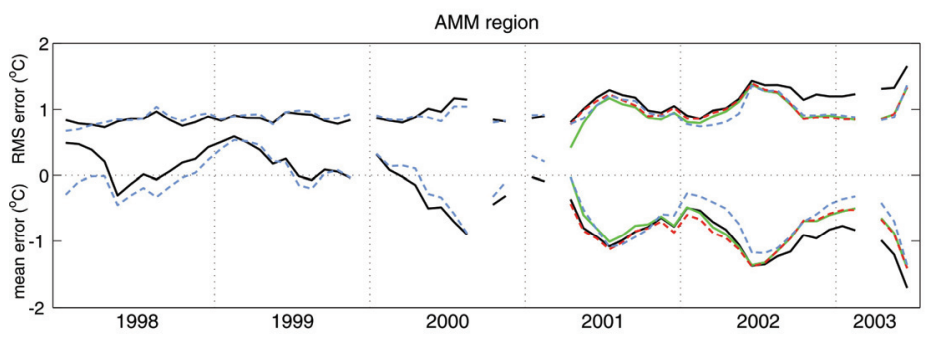

Fig. 3 Comparison with AVHRR sea surface temperature data. RMS errors (top set of lines) and mean errors (model - observed, bottom lines) for AMMFOAM (black solid line), AMM-NCOM (green solid line), AMM-NCOM(FIC) (red dashed line) and AMM-climate (blue dashed line). The top figure is for calculations over the whole domain and

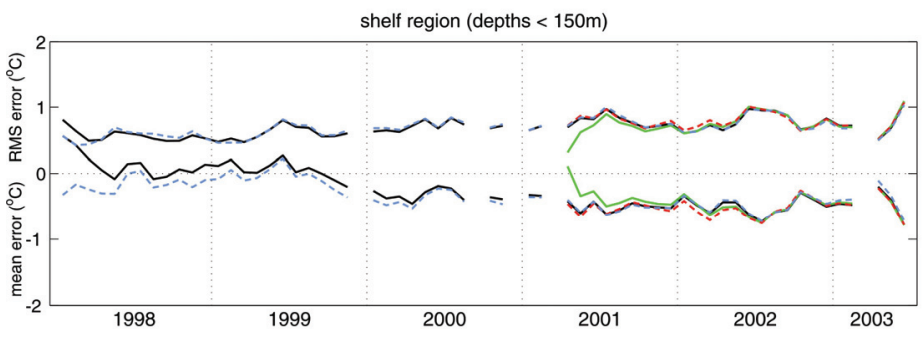
the bottom one is for just the shelf area (coloured shading in Fig. 1) 


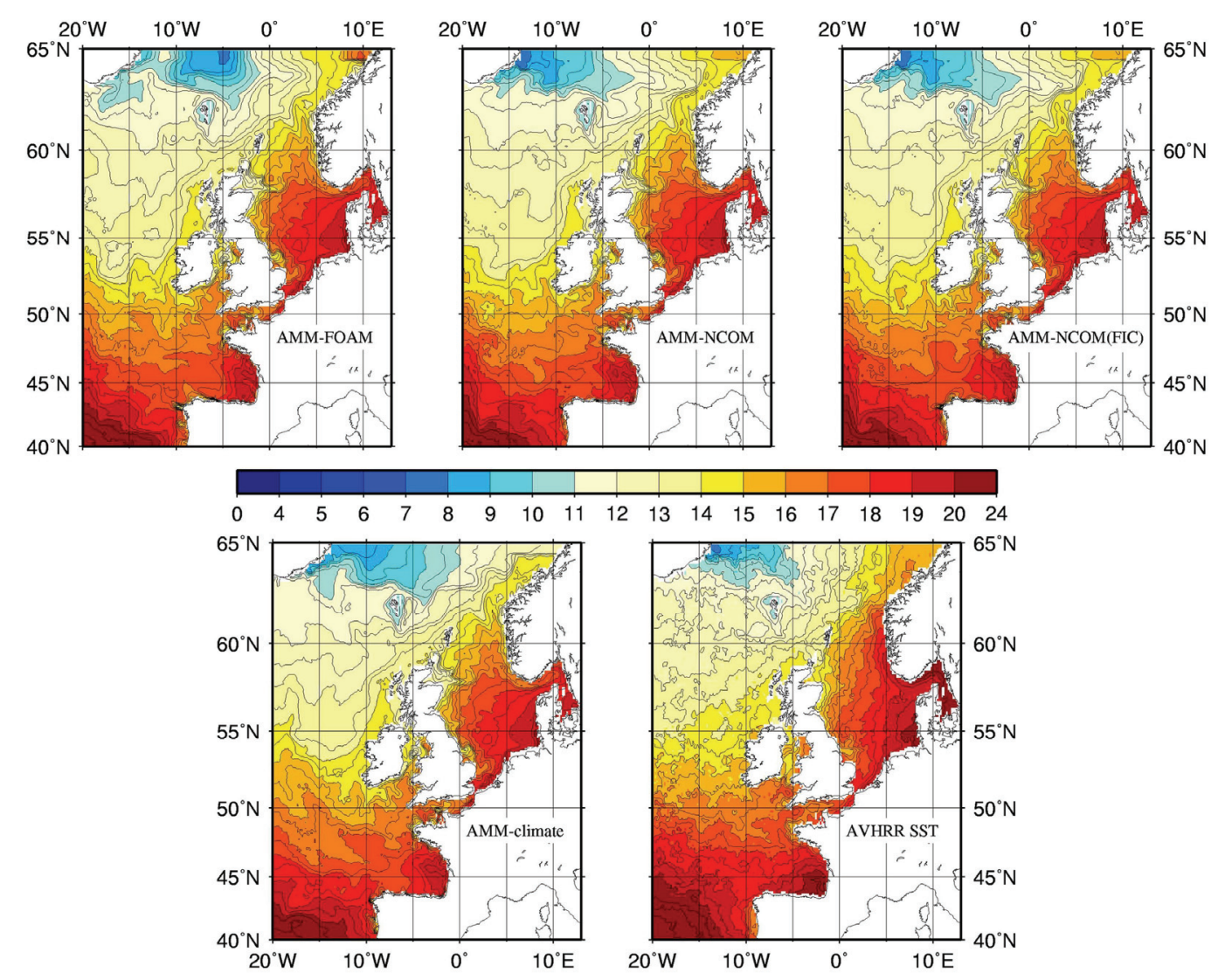

Fig. 4a Mean sea surface temperature fields $\left({ }^{\circ} \mathrm{C}\right)$ for August 2002. The observed AVHRR data from the NOAA/NASA Ocean Pathfinder satellite are averaged over times that data are available and the model data are averaged using the same times. The model runs are defined in Table 1

The depth of the mixed layer is calculated as the depth at which the density has increased from that at the reference depth of $6 \mathrm{~m}$ by an amount equivalent to a decrease in temperature of $0.5^{\circ} \mathrm{C}$. Over most of the domain, the summer mixed layer depths of the model results are deeper than those of the NCOM model by between $\sim 15-20 \mathrm{~m}$ in the deep regions and $\sim 4-6 \mathrm{~m}$ in the North Sea. In the deeper regions, the summer mixed layer depths taken from climatological fields are in closer agreement with the NCOM data than with the POLCOMS results. Thus, the vertical mixing in POLCOMS appears too deep, contributing to the model underestimation of sea surface temperature. Between the POLCOMS results, the NCOM data and the climatology, there is no dataset with overall shallower or deeper levels of the permanent thermocline. The FOAM model dataset is a combination of model runs and only data at the AMM boundary are available. At the AMM boundary, the FOAM mixed layer depths tend to be shallower than those of NCOM in the winter, and deeper in summer.

Sea surface temperature maps for August 2002 and February 2003 (Fig. 4) show the spatial details behind the statistics in Fig. 3. The model runs all exhibit similar features on the shelf and overall show good spatial correlations with AVHRR (correlation coefficients for model versus AVHRR for February 2003 are $r=0.96$ for AMM-FOAM and $r=0.98$ for the other three runs).

In August 2002, features of the model output in agreement with satellite data include the southwards flowing tongue of cool water along the coast of northeast England and a patch of cooler water on the Faeroe plateau. The mean differences between model and satellite sea 
surface temperatures are generally less than $0.3^{\circ} \mathrm{C}$ over most of the North Sea. The model does less well in the Norwegian Coastal Current where too much mixing causes the model to underestimate the SST by $2-3^{\circ} \mathrm{C}$, and in the southwest corner of the model where the water is generally too cold by $\sim 1^{\circ} \mathrm{C}$. The accuracy of AMM-FOAM result at the northern boundary is reduced by the FOAM boundary data being $\sim 2.5^{\circ} \mathrm{C}$ too warm off the coast of Iceland and $\sim 3.5^{\circ} \mathrm{C}$ too cold around $5^{\circ} \mathrm{W}$, compared to the satellite data.

Several features of the large-scale near-surface circulation (Hansen and Østerhus, 2000) are apparent in the February 2003 AVHRR SST data (Fig. 4b). Around $55-60^{\circ} \mathrm{N}, 15-20^{\circ} \mathrm{W}$, is an area of warmer water associated with the northeastwards flowing North Atlantic Current, while to the east of that, and extending northwards all along the edge of the continental shelf, is an area of warm water associated with the Continental Slope Current. The Norwegian Coastal Current is also visible, as a band of cold water along the coast of Norway. The location of the Iceland-Faeroes Front to the north of the Faeroe Islands is shown by a strong change in the surface temperature. Except for the AMM-climate run, the models recreate well the surface temperature fields associated with the North Atlantic Current and the Continental Slope Current. In the AMM-climate run, the warm water extends too far northwards west of $15^{\circ} \mathrm{W}$. All of the model results show evidence of the Iceland-Faeroes Front but generally locate it further south than shown in the satellite data. The AMM-FOAM run is up to $3^{\circ} \mathrm{C}$ too cold in this region and the cold water extends too far east, the model runs forced by NCOM boundary data have much better agreement with the satellite data than the AMM-FOAM run. The model surface temperatures are all $\sim 0.5^{\circ} \mathrm{C}$ too warm in the Norwegian Coastal Current, when compared to satellite data, but otherwise slightly too cold over the rest of the North Sea.

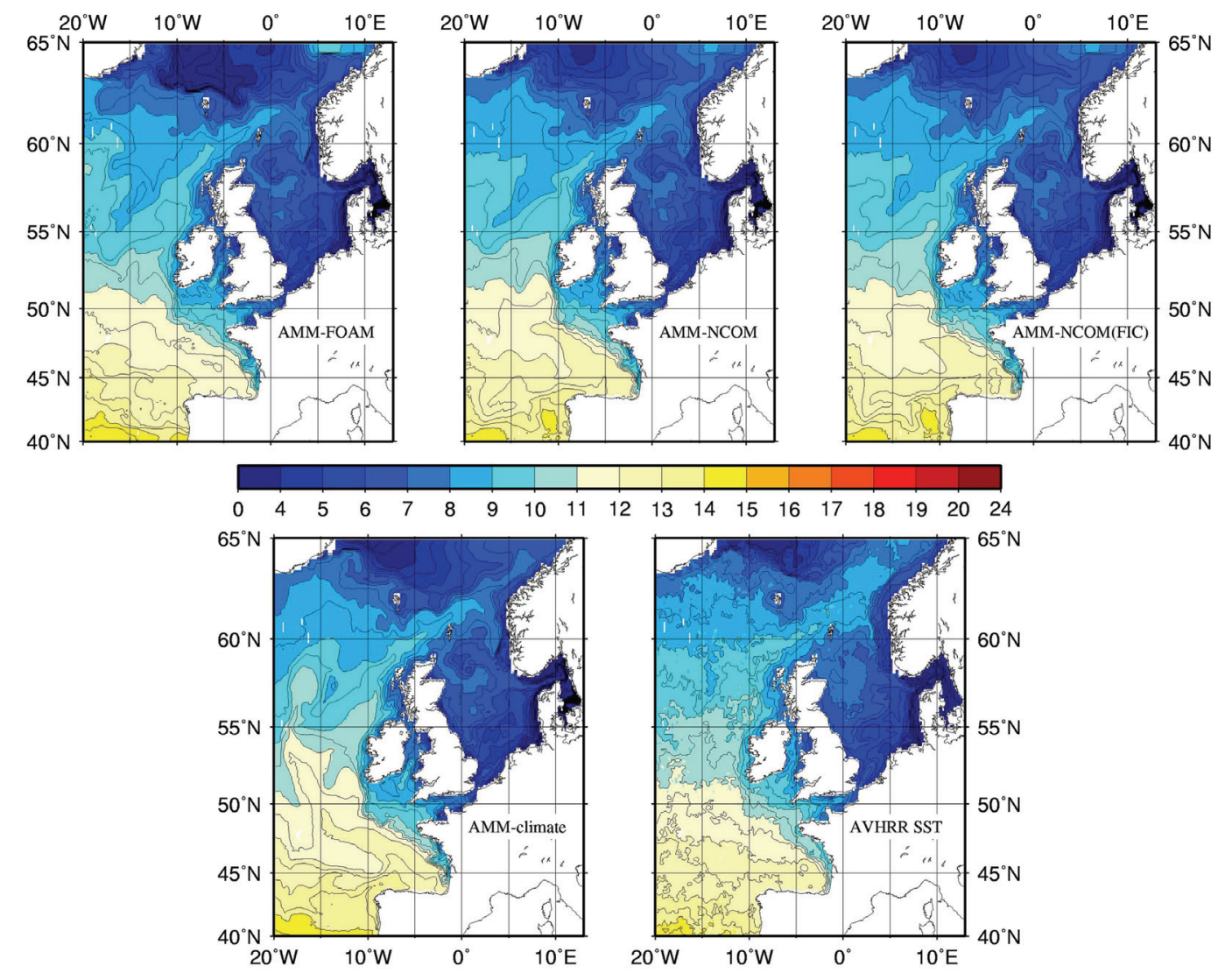

Fig. 4b As for Fig. 4a, but for February 2003 


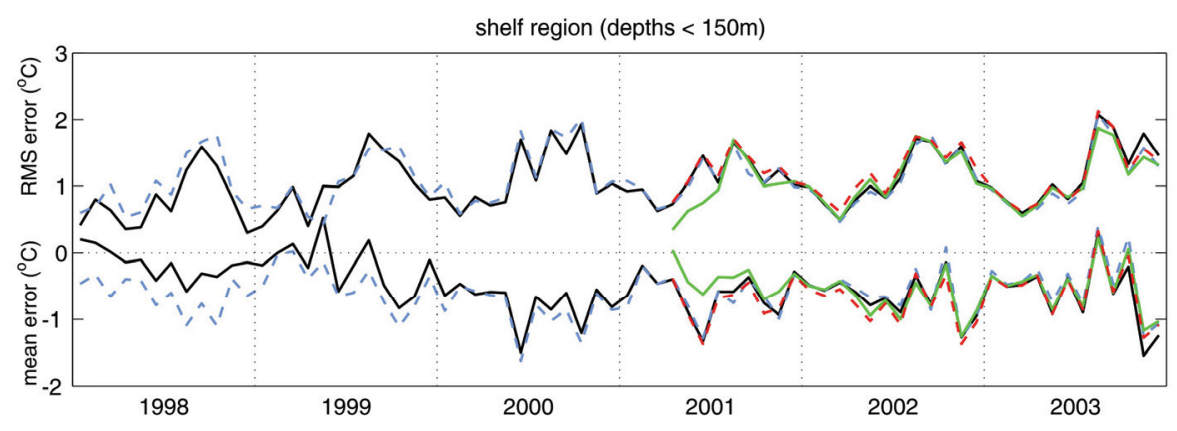

Fig. 5 Errors in near-bed modelled temperatures compared to ICES data over the shelf area (coloured shading in Fig. 1). RMS errors (top set of lines) and mean errors (model - observed, bottom lines) for AMM-FOAM (black solid line), AMM-NCOM (green solid line), AMM-NCOM(FIC) (red dashed line) and AMM-climate (blue dashed line)

The sensitivity of the near-bed temperature field on the shelf to the initial and boundary conditions is studied by comparing model results with observed data from the International Council for the Exploration of the Sea (ICES, http://www.ices.dk/Ocean/aspx/HydChem/HydChem.aspx). From 1998-2003 in the shelf region, there are 3477 temperature measurements taken within $10 \mathrm{~m}$ of the sea bed. The number of observations per month varies between 3 and 116 with an average of 48, with most of the data being located in the North Sea and the shelf region south of Ireland and west of France, and a scattering of points in the Irish Sea and north of Scotland. For each observation, the model temperature field for that day is interpolated to the location and the difference between the modelled and observed values is used to calculate the mean and RMS errors for each month (Fig. 5).

There is a strong seasonal signal in the near-bed RMS errors, ranging from $\sim 0.4-0.5^{\circ} \mathrm{C}$ in spring to $\sim 1.6-2.1^{\circ} \mathrm{C}$ in autumn with average values for each run of $\sim 1.1^{\circ} \mathrm{C}$. Initially, the near-bed errors show the models increasingly underestimating the temperature but, from 2000 onwards, they fluctuate around a value of $\sim 0.6^{\circ} \mathrm{C}$ too cold.

The two NCOM-forced runs show that the affect of the initial condition on the near-bed errors has reduced appreciably after nine months of integration. While the major features of the error time series are similar for all of the model runs, there are still differences between them after 33 months of model time.

\subsection{Volume fluxes and currents}

Daily-mean net volume fluxes are calculated for the flows through the 12 sections shown in Fig. 1 for AMM-FOAM, AMM-climate, AMM-NCOM and AMM-NCOM(FIC). The sections are chosen to cross important pathways for the movement of water along the edge of the continental shelf and into and out of the North Sea and the Irish Sea. The volume fluxes are calculated by dividing each section into $1 \mathrm{~km}$ lengths and estimating the flow through each $1 \mathrm{~km}$ length by integrating through the water column at surrounding grid points and interpolating.

Table 2 shows the mean volume fluxes through each section and the standard deviations of the time series and table 3 shows the Root Mean Square (RMS) differences and correlation coefficients between the different time series, calculated from daily-mean current fields during 2002 and 2003. Where available, observed data have been included in table 2. Both observed data and model results show large inter-annual variability and the observed means are not from the same time frame or exactly co-located in space with the model data and so 
are only an approximate guide to model accuracy. The agreement between the four model runs is generally better for the on-shelf sections in St. George's Channel, the Dover Strait and the northern North Sea than for the other sections, with correlation coefficients exceeding 0.95 in these areas.

The largest difference between the model runs occurs at section 1 in the Bay of Biscay. The model time series have low correlations with each other and high RMS differences.

For the Dover Strait section, the model results are in good agreement with one other and highly correlated. However, the mean flux of 0.01-0.02Sv into the North Sea is nearly an order of magnitude smaller than the 0.094Sv calculated by Prandle et al (1996) from HF radar and bottom-mounted acoustic Doppler current profiler measurements, although the value is within one standard deviation of the model mean. The model results agree on a net northwards flow of $0.14 \mathrm{~Sv}$ through St. George's Channel, which corresponds to the $0.11-$ 0.14Sv volume flux observed by Brown and Gmitrowicz (1995) through the North Channel of the Irish Sea and the value of $0.077 \pm 0.013 \mathrm{~Sv}$ given by Knight and Howarth (1999).

The AMM-FOAM, AMM-NCOM and AMM-NCOM(FIC) runs predict a northwards volume flux $\sim 2 \mathrm{~Sv}$ through section 4, south of Porcupine Bank, but the AMM-climate results contradict this by predicting a mean southwards flow. The difference in the results is clarified by examining the spatial distribution of the 2002/2003 mean south-to-north current speed across section 5 (not shown). At the shelf break $\sim 10.8^{\circ} \mathrm{W}$, the two NCOM-forced runs have a concentrated northwards flowing jet with peak average annual-mean speeds of $\sim 0.04 \mathrm{~ms}^{-1}$, while the AMM-FOAM and AMM-climate runs achieve peaks of only $0.02 \mathrm{~ms}^{-1}$ with the AMM-climate current displaced several grid boxes to the west. The AMM-climate run has mostly weak southwards flow in the deep water over the rest of the section while the other three runs have another jet of northwards flowing current at $\sim 11.5-12^{\circ} \mathrm{W}$. Pingree and Le Cann (1989) confirm northwards-flowing currents in water of $960-1000 \mathrm{~m}$ depth at $51-52^{\circ} \mathrm{N}$, $11-12^{\circ} \mathrm{W}$.

\begin{tabular}{|c|c|c|c|c|c|c|c|c|c|c|}
\hline \multirow{2}{*}{\multicolumn{2}{|c|}{ section }} & \multirow{2}{*}{$\begin{array}{l}\text { observed } \\
\text { volume } \\
\text { flux (Sv) }\end{array}$} & \multicolumn{4}{|c|}{ mean volume fluxes (Sv) } & \multicolumn{4}{|c|}{ standard deviations (Sv) } \\
\hline & & & \multirow{2}{*}{$\begin{array}{r}\text { AMM- } \\
\text { FOAM } \\
7.91 \\
\end{array}$} & \multirow{2}{*}{$\begin{array}{r}\begin{array}{c}\text { AMM- } \\
\text { climate }\end{array} \\
20.87 \\
\end{array}$} & \multirow{2}{*}{$\begin{array}{r}\text { AMM- } \\
\text { NCOM } \\
23.22\end{array}$} & \multirow{2}{*}{$\begin{array}{r}\begin{array}{r}\text { AMM- } \\
\text { NCOM } \\
(\text { FIC) }\end{array} \\
15.81 \\
\end{array}$} & \multirow{2}{*}{$\begin{array}{l}\text { AMM- } \\
\text { FOAM } \\
16.15\end{array}$} & \multirow{2}{*}{$\begin{array}{r}\begin{array}{c}\text { AMM- } \\
\text { climate }\end{array} \\
12.90\end{array}$} & \multirow{2}{*}{$\begin{array}{r}\text { AMM- } \\
\text { NCOM } \\
11.83 \\
\end{array}$} & \multirow{2}{*}{$\begin{array}{r}\text { AMM- } \\
\text { NCOM } \\
\text { (FIC) } \\
8.55 \\
\end{array}$} \\
\hline 1 & Bay of Biscay $45^{\circ} \mathrm{N}$ & & & & & & & & & \\
\hline 2 & Dover Strait & 0.094 & 0.02 & 0.01 & 0.01 & 0.02 & 0.15 & 0.15 & 0.15 & 0.15 \\
\hline 3 & St George's Channel & & 0.14 & 0.14 & 0.15 & 0.14 & 0.09 & 0.09 & 0.10 & 0.10 \\
\hline 4 & Porcupine Bank (south) & & 2.34 & -1.57 & 1.70 & 1.79 & 3.77 & 3.25 & 3.75 & 4.42 \\
\hline 5 & Porcupine Bank (west) & & 2.06 & 1.29 & 3.95 & 3.96 & 2.91 & 2.46 & 2.31 & 2.90 \\
\hline 6 & Porcupine Bank (east) & 0.24 & 0.09 & 0.11 & 0.23 & 0.19 & 0.49 & 0.50 & 0.47 & 0.46 \\
\hline 7 & Shelf current $57.67^{\circ} \mathrm{N}$ & $1.2-2.2$ & 1.62 & 2.02 & 1.79 & 1.76 & 1.43 & 1.43 & 1.34 & 1.14 \\
\hline 8 & Faeroe to Shetland & $4-7$ & 2.63 & 3.72 & 2.93 & 2.30 & 3.33 & 2.49 & 1.99 & 2.12 \\
\hline 9 & Scotland to Orkney & & 0.04 & 0.04 & 0.04 & 0.04 & 0.05 & 0.05 & 0.05 & 0.05 \\
\hline 10 & Orkney to Shetland & -0.3 & -0.47 & -0.48 & -0.50 & -0.49 & 0.45 & 0.44 & 0.44 & 0.44 \\
\hline 11 & Shetland to Norway Trench & -0.6 & -0.81 & -0.80 & -0.74 & -0.80 & 0.43 & 0.41 & 0.41 & 0.41 \\
\hline 12 & Norway Trench to Norway & 1.8 & 1.33 & 1.33 & 1.28 & 1.34 & 0.67 & 0.66 & 0.65 & 0.64 \\
\hline
\end{tabular}

Table 2 Mean and standard deviations of the daily-mean volume fluxes through the 12 sections (Fig. 1) for four model runs (Table 1) over 2002 and 2003. All fluxes are in Sverdrups $\left(1 \mathrm{~Sv}=10^{6} \mathrm{~m}^{3} \mathrm{~s}^{-1}\right)$ with positive values for north and eastwards fluxes. Observed data for section 2 from Prandle et al. (1996), 6 from Fernand et al. (2006), 7 and 8 from Huthnance and Gould (1989) and 10, 11 and 12 from Otto et al. (1990) 
The models all agree on a northwards flux $\sim 1-4 \mathrm{~Sv}$ through section 5, west of Porcupine Bank but the RMS differences are high. All the model runs agree that a much smaller northwards flux occurs through the Porcupine Bank (section 6) than further west along the edge of the continental shelf (section 5). The AMM-NCOM run gives a flux close to the observed $(0.24 \mathrm{~Sv}$, Fernand et al, 2006) and is about twice the values obtained from AMM-FOAM and AMM-climate, although all results are highly correlated with one another.

There is good agreement on the mean flux through section 7 across the shelf edge at $57.67 \mathrm{~N}$, with fluxes of 1.6-2.0Sv, in accord with observations $(1.2-2.2 \mathrm{~Sv}$ inshore of the $2000 \mathrm{~m}$ contour, Huthnance and Gould, 1989). However, except for the two runs using NCOM boundary data, the results are not highly correlated with one another. The models give a mean northwards flux of 2-4Sv through the Faeroe to Shetland section (compared with the observed value of 3.8Sv of Atlantic water through the Faeroe-Shetland channel, Østerhus et al, 2005), but again are not highly correlated except for the NCOM runs. The relatively large RMS differences (compared to the mean) between the fluxes through sections 7 and 8 show that, even though the mean fluxes compare well with observations, on a day-to-day basis the flows are very different.

The model boundary conditions have little effect on the volume fluxes into the northern North Sea through the Scotland to Orkney and Orkney to Shetland sections, with mean values in close agreement $(0.04 \mathrm{~Sv}$ and $0.47-0.50 \mathrm{~Sv}$, respectively). The inflow between Shetland and the $295 \mathrm{~m}$ contour in the Norwegian Trench (section 11 ) changes by $\sim 10 \%$ depending on the boundary condition used. If the $150 \mathrm{~m}$ contour is used as the eastward end of the section then the volume fluxes are in better agreement with one another $(-0.46 \mathrm{~Sv}$ for all runs), that is, the volume fluxes through the shallower regions are less dependent on which boundary condition is used than those through sections that include deeper regions. Incidentally, this gives an estimate for the mean southwards volume flux along the western edge of the Norwegian Trench of $0.28-0.35 \mathrm{~Sv}$, compared to the observed value of $0.7-1.11 \mathrm{~Sv}$ (Otto et al., 1990). The northerly outflow of $\sim 1.3 \mathrm{~Sv}$ between the $295 \mathrm{~m}$-depth contour in the Norwegian Trench and the Norwegian coast (section 12) compares well with the observed value and approximately balances the inflow. The volume fluxes calculated from the model runs are all highly correlated (correlation coefficients $>0.95$ ) with one another at the four northern North Sea sections.

\begin{tabular}{|c|c|c|c|c|c|c|c|c|c|c|c|c|c|}
\hline \multirow{2}{*}{\multicolumn{2}{|c|}{ section }} & \multicolumn{6}{|c|}{ RMS differences (Sv) } & \multicolumn{6}{|c|}{ correlation coefficient } \\
\hline & & \multirow{2}{*}{$\begin{array}{r}\text { E1-E3 } \\
22.36\end{array}$} & \multirow{2}{*}{$\begin{array}{r}\text { E1-E2 } \\
20.77\end{array}$} & \multirow{2}{*}{$\begin{array}{r}\text { E1-E4 } \\
20.45\end{array}$} & \multirow{2}{*}{$\begin{array}{r}\text { E3-E2 } \\
14.71\end{array}$} & \multirow{2}{*}{$\begin{array}{r}\text { E3-E4 } \\
12.22\end{array}$} & \multirow{2}{*}{$\begin{array}{r}\text { E4-E2 } \\
15.30\end{array}$} & \multirow{2}{*}{$\begin{array}{r}\text { E1-E3 } \\
0.35\end{array}$} & \multirow{2}{*}{$\begin{array}{r}\text { E1-E2 } \\
0.39\end{array}$} & \multirow{2}{*}{$\begin{array}{r}\text { E1-E4 } \\
-0.08\end{array}$} & \multirow{2}{*}{$\begin{array}{r}\text { E3-E2 } \\
0.31\end{array}$} & \multirow{2}{*}{$\begin{array}{r}\text { E3-E4 } \\
0.59\end{array}$} & \multirow{2}{*}{$\begin{array}{r}\text { E4-E2 } \\
0.14\end{array}$} \\
\hline 1 & Bay of Biscay $45^{\circ} \mathrm{N}$ & & & & & & & & & & & & \\
\hline 2 & Dover Strait & 0.01 & 0.01 & 0.01 & 0.01 & 0.01 & 0.01 & 1.00 & 1.00 & 1.00 & 1.00 & 1.00 & 1.00 \\
\hline 3 & St George's Channel & 0.02 & 0.02 & 0.02 & 0.02 & 0.02 & 0.02 & 0.98 & 0.98 & 0.99 & 0.98 & 0.98 & 0.99 \\
\hline 4 & Porcupine Bank (south) & 5.10 & 5.97 & 5.62 & 5.26 & 4.23 & 5.65 & 0.09 & 0.18 & 0.07 & 0.31 & 0.47 & 0.33 \\
\hline 5 & Porcupine Bank (west) & 4.83 & 3.10 & 4.99 & 4.38 & 2.26 & 4.86 & -0.44 & 0.38 & -0.26 & -0.07 & 0.64 & -0.14 \\
\hline 6 & Porcupine Bank (east) & 0.19 & 0.13 & 0.16 & 0.19 & 0.09 & 0.18 & 0.97 & 0.97 & 0.97 & 0.96 & 0.98 & 0.95 \\
\hline 7 & Shelf current $57.67^{\circ} \mathrm{N}$ & 0.95 & 1.12 & 1.01 & 0.95 & 0.56 & 1.12 & 0.78 & 0.73 & 0.72 & 0.78 & 0.91 & 0.66 \\
\hline 8 & Faeroe to Shetland & 3.43 & 3.67 & 3.20 & 2.62 & 1.00 & 2.88 & 0.25 & 0.30 & 0.39 & 0.39 & 0.93 & 0.42 \\
\hline 9 & Scotland to Orkney & 0.01 & 0.01 & 0.01 & 0.01 & 0.01 & 0.01 & 0.99 & 0.99 & 0.99 & 0.99 & 1.00 & 0.99 \\
\hline 10 & Orkney to Shetland & 0.07 & 0.07 & 0.07 & 0.07 & 0.04 & 0.07 & 0.99 & 0.99 & 0.99 & 0.99 & 1.00 & 0.99 \\
\hline 11 & Shetland to Norway Trench & 0.15 & 0.13 & 0.14 & 0.14 & 0.09 & 0.14 & 0.95 & 0.96 & 0.95 & 0.95 & 0.98 & 0.94 \\
\hline 12 & Norway Trench to Norway & 0.15 & 0.15 & 0.16 & 0.16 & 0.10 & 0.17 & 0.98 & 0.98 & 0.97 & 0.97 & 0.99 & 0.97 \\
\hline
\end{tabular}

Table 3 RMS differences between the daily-mean volume fluxes through the 12 sections (Fig. 1) for four model runs over 2002 and 2003. E1 is AMM-FOAM, E2 is AMM-climate, E3 is AMM-NCOM and E4 is AMMNCOM(FIC) (Table 1). All fluxes are in Sverdrups $\left(1 \mathrm{~Sv}=10^{6} \mathrm{~m}^{3} \mathrm{~s}^{-1}\right)$. Also given are the correlation coefficients between each set of model output with a $99.95 \%$ significance level of 0.12 
Plots of the thirty-day running-mean volume fluxes (Fig. 6), calculated from the daily-mean values for the 12 sections, confirm the good agreement between the four model runs for the sections through the shallower regions (sections 2, 3,9 and 10), and to a lesser extent sections 11 and 12, which include the deeper regions of the Norwegian Trench. The total inflow through sections 9-11 is correlated with the outwards flux through section 12 with correlation coefficients of $0.93,0.94,0.92$ and 0.87 for AMM-FOAM, AMM-climate, AMM-NCOM and AMM-NCOM(FIC), respectively. The volume fluxes through section 1 in the Bay of Biscay show some agreement between the model runs during 2002 with a minimum flux in the summer but are widely different during 2003.

Comparing the volume fluxes for the two runs forced by NCOM boundary conditions and using different initial conditions shows the regions where the choice of initial condition makes a difference to the model dynamics through the major pathways of the northeast Atlantic. On the continental shelf, the effect of the initial condition is small. The shelf current at $57.67^{\circ} \mathrm{N}$ and the flow along the eastern side of the Faeroe-Shetland channel are both affected by the initial condition but the results remain close and are highly correlated. Of the sections studied, three - in the Bay of Biscay (1), and south (4) and west (5) of the Porcupine Bank - were greatly affected by the initial condition. These sections cut across the continental slope from shallow to deep water, but so do sections 7 and 10, which are less affected by the initial condition so the inclusion of deep water is not the whole reason for the difference. The three sections are all in the southwestern corner of the model and it might be that the dynamics of this region are highly dependent on the initial conditions.

The AMM-FOAM and AMM-climate runs have in common the elevation and current boundary conditions but differ in temperature and salinity boundary and initial conditions. In addition to the three southwestern sections which are affected by changing the initial conditions alone, the volume fluxes through the eastern side of the Faeroe-Shetland channel and, to a lesser extent, the shelf current at $57.67^{\circ} \mathrm{N}$ are affected by the change in initial and boundary temperature and salinity data.

The North Atlantic Oscillation is a major mode of variability in the Northern Hemisphere atmosphere and exerts a strong control on the climate, especially in the winter. For all model runs, the monthly-mean volume fluxes through sections 9,10 and 12 are correlated with the monthly mean NAO index (http://www.cru.uea.ac.uk/ timo/projpages/nao_update.htm) at the $99 \%$ significance level $(r=0.52)$. Volume fluxes through the other sections are not correlated at that level. Winter mean (December to March) values of the NAO index vary from 0.79 in $2001 / 2002$ to 0.40 in $2002 / 2003$ and -0.2 in $2003 / 2004$, indicating very different average weather conditions over the North Atlantic in 2002 and 2003. For volume fluxes across several of the sections crossing deeper water, particularly section 8, the AMM-climate run displays a strong seasonal signal repeated in 2002 and 2003, which is absent in the other model runs (Fig. 6). The climate temperature and salinity boundary conditions are missing information on inter-annual variability that exists in the FOAM and NCOM models and this appears to impact on the fluxes in the deeper regions of the model. 

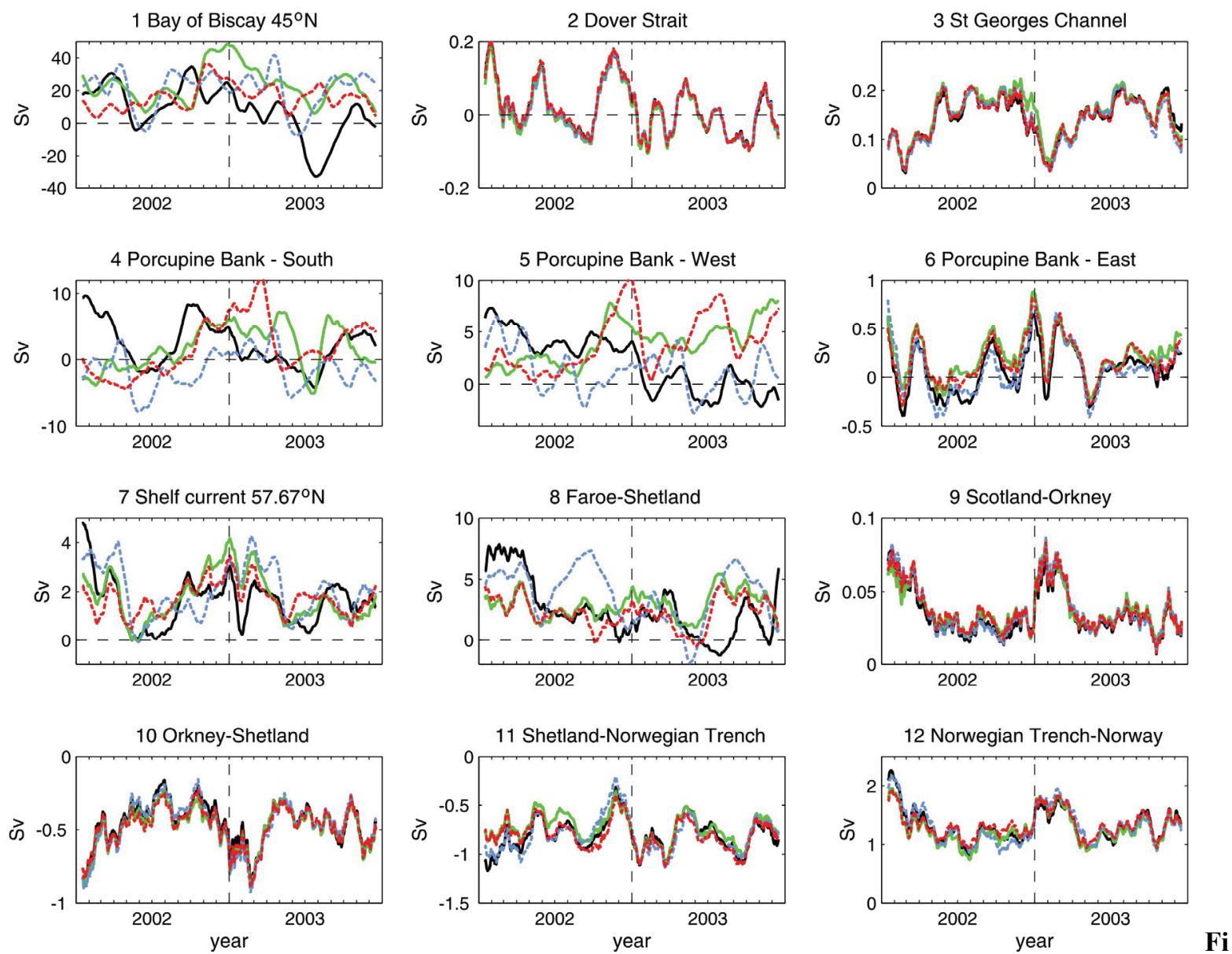

g. 6 AMM 30-day running mean volume fluxes normal to the sections shown in Fig. 1 from AMM-FOAM (black solid lines), AMM-NCOM (green solid lines), AMM-climate (blue dashed lines) and AMM-NCOM(FIC) (red dashed lines). Positive values denote fluxes towards the north and east

\subsection{Sea surface height (SSH) fields}

Satellite altimetry data provides another useful source of model validation information, which in deep, non-tidally stirred waters, through a geostrophic relationship can be related approximately to the surface currents. Using elevation data output at hourly intervals, average sea surface height (SSH) fields for the final two years of the simulations (2002-2003) are constructed for each model run. The effect of atmospheric pressure is removed by using the inverse barometer relationship. The SSH along each section in Fig. 1 is calculated and, for each section and each model run, the mean SSH along the section is subtracted so that all lines are plotted around a zero mean (Fig. 7).

The modelled SSH are in close agreement with each other for all of the sections on the shelf, showing that the choice of boundary condition has little affect on the mean SSH here, where the tidal signal tends to dominate. The shape of the sea surface determines the geostrophic currents in the upper ocean and the agreement between the models reinforces the volume flux results (Fig. 6). Four of the sections along the shelf edge - in the Bay of Biscay (1), east of Porcupine Bank (6), the shelf current (7) and the Faeroe-Shetland current (8) - also show close agreement between the model SSHs, an indication that the large-scale upper-level geostrophic flow along the shelf edge is not strongly affected by the choice of boundary condition. Sections 4 and 5, south and west of Porcupine Bank, show more scatter between the different model runs. The AMM-climate results are most different from the other runs and 
this might be due to an inconsistency in mixing climate temperature and salinity boundary conditions with FOAM elevation and current boundary conditions.

The model results are compared to mean absolute sea level (Fig. 7) for 1992-2002, calculated from GRACE satellite data, drifter and wind fields (Niiler et al., 2003; Maximenko and Niiler, 2005). The satellite data are on a $0.5^{\circ}$ resolution global grid and there are no data near land for sections 2, 3, 9, 10 and 12. As for the model data, the along-section mean is subtracted for each section. Except for section 5, west of Porcupine Bank, and the AMM-climate results in the section south of Porcupine Bank (4), there is general agreement between the modelled and observed sea levels. The model results and satellite data agree well for the two sections through the Bay of Biscay (1) and the Faeroe-Shetland current (8). For the section through the shelf current (7) both models and observations show a gentle slope at the western end, increasing around $8.5-9^{\circ} \mathrm{W}$ and reducing further east, although in the eastern part of the section the slope of the model sea surface is much greater than the observed.
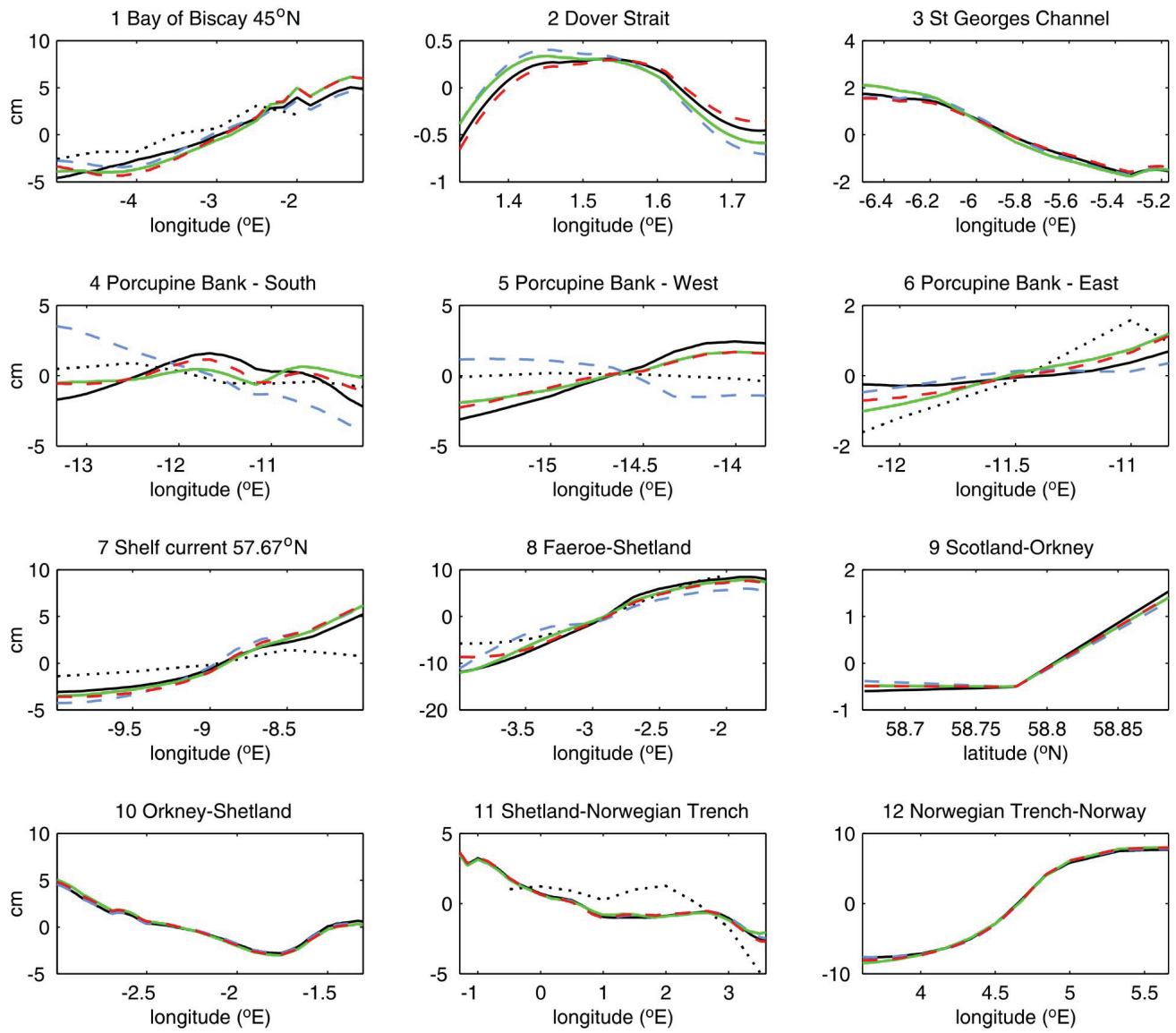

Fig. 7 Comparison of observed and modelled mean sea surface height (cm) along the sections shown in Fig. 1. AMM-FOAM (black solid line), AMM-NCOM (green solid line), AMM-NCOM(FIC) (red dashed line), AMMclimate (blue dashed line) and satellite-derived (black dotted line) data. 


\subsection{Tracers}

To investigate the on-shelf flux of material, passive tracer transport is calculated in the model runs. At 0 hours on the $1^{\text {st }}$ January 2002, a tracer was released into the model domain in each run. The tracer was given the value of $100 \mathrm{~m}^{-3}$ and placed throughout the water column wherever the undisturbed water depth in the model was greater than $2000 \mathrm{~m}$. This is in three regions - the whole of the southwestern corner of the model, into the Bay of Biscay and extending northwards into the Rockall Trough, the area between $\sim 14-20^{\circ} \mathrm{W}$ and $59-62^{\circ} \mathrm{N}$ (the eastern edge of the Iceland basin) and the deep region near the northern boundary (the southern Norwegian Sea). The tracer is passive but allowed to advect and diffuse with the model flow.

Six months after release, the tracer has in all cases been transported along the edge of the continental shelf to north of the Shetland Islands (Fig. 8a). The current that flows into the North Sea between Orkney and Shetland is clearly visible and, for the AMM-FOAM and AMM-climate runs, the tracer has been transported further along the shelf edge and is beginning to turn southwards down the western edge of the Norwegian Trough. None of the model runs show evidence of cross-slope transport from the Bay of Biscay onto the shelf region west of France but all show that there is flow onto the shelf to the west of Ireland and west and north of Scotland. Only a small amount of tracer has been transported into the central and southern North Sea, the Irish Sea and the Celtic Sea. The AMM-FOAM and AMM-climate runs have transported tracer further north along the coast of Norway than the two runs forced with NCOM boundary data. The same two model runs transport tracer from the Iceland Basin eastwards over the Iceland-Faeroe ridge and north of the Faeroe Islands, a flow that is also absent in the NCOM-forced runs. The AMM-FOAM run has retained the tracer in the region of deep water near the northern boundary of the model, in the other three models the tracer has been transported away.

Two years after release (Fig. 8b), the tracer has reached most of the model domain. The AMM-FOAM and AMM-climate results show evidence of stronger northwards flow along the edge of the continental shelf as much more tracer has reached the area west of Norway than in the models forced with NCOM boundary data. Significantly higher concentrations of tracer have been advected northwards by the AMM-FOAM model than the AMM-climate model. There is also much less mixing of the tracer in the southwest corner of the domain in AMM-climate. The details of the density structure of the boundary conditions have a large impact on the transport of the tracer in the deeper water and impacting onto the shelf region. All of the models show cross-slope transport of the tracer to the west of France, into the English Channel and through the Dover Strait. Tracer has now entered the Irish Sea but the water around Ireland and in the southern North Sea still has much lower concentrations than most other regions. 
$\mathbf{a}$

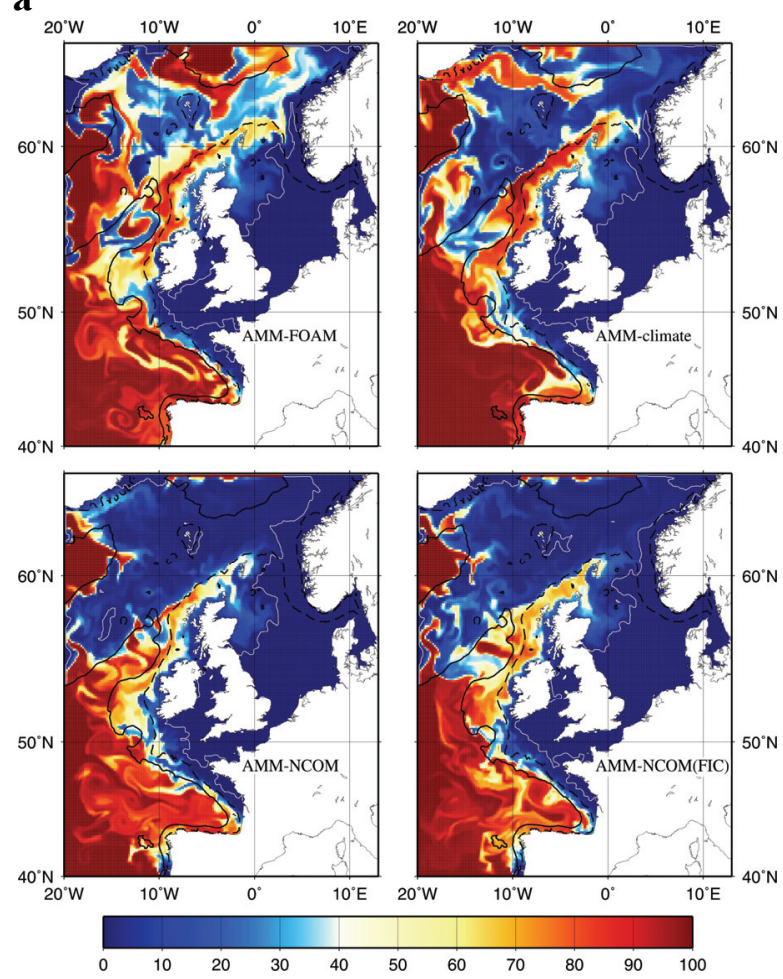

b

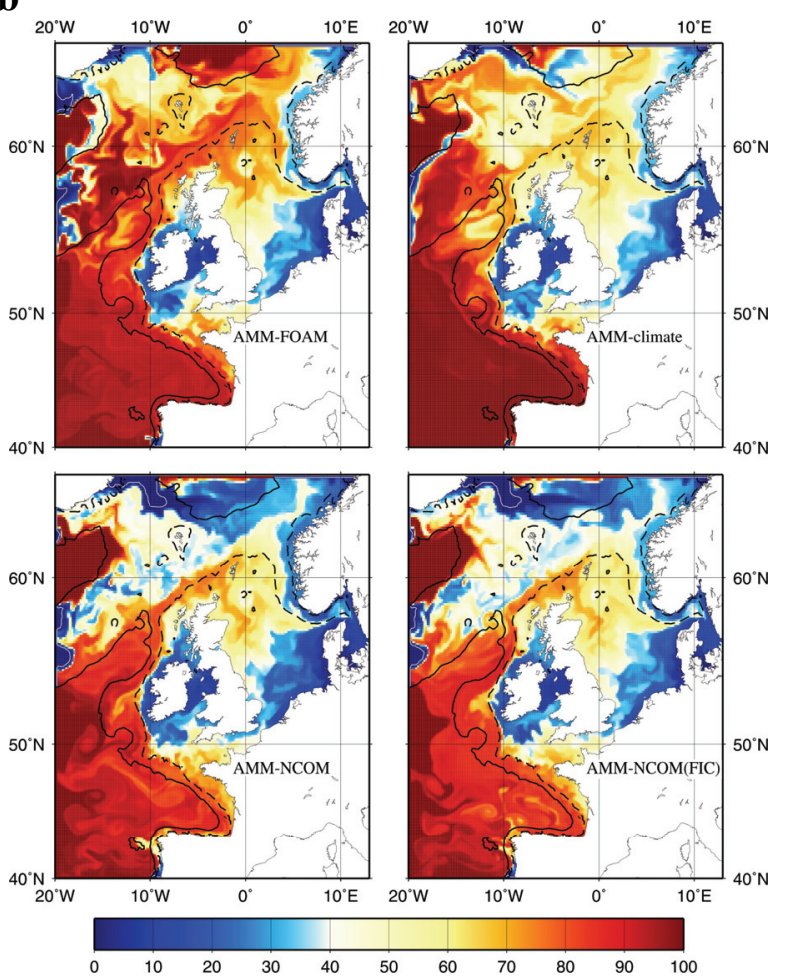

Fig. 8a Extent of the tracer concentration at the sea surface six months after release. Tracer of value $100 \mathrm{~m}^{-3} \mathrm{was}$ released on $1^{\text {st }}$ January 2002 in regions where the depth is greater than $2000 \mathrm{~m}$. The black solid line is the $2000 \mathrm{~m}$ isobath. The black dashed line is the $150 \mathrm{~m}$ isobath representing the extent of the shelf area. The white contour shows the limit of the region where the value of the tracer exceeds $0.1 \mathrm{~m}^{-3}$. b As for a, but 24 months after release of the tracer

\section{Discussion}

Two operational ocean models covering the northeast Atlantic provide boundary and initial conditions for a regional model of the Atlantic Margin (AMM). To investigate the value to the regional model of using boundary conditions from the ocean models, a hybrid data set comprising temperature and salinity climatologies and current and elevations from one of the models (FOAM) is also used to force the AMM.

The results of the Atlantic Margin model compare well with observations of sea surface temperature. On the shelf, the sea surface temperature errors of the two runs using NCOM boundary data but differing initial conditions suggest that, after 15 months of model time, the effect of the temperature and salinity initial conditions is negligible and the model dynamics and meteorological forcing have become dominant. When the deeper regions of the Atlantic Margin domain are included in the comparison, the density-related boundary conditions become important and the NCOM boundary conditions give smaller RMS errors than the FOAM boundary conditions. The run using climate data temperature and salinity boundary and initial conditions gave the smallest SST errors when calculated over the whole domain. In contrast to the statistics, there is some evidence from spatial plots of SST in the AMM-climate run of a too-strong northwards current near $15-20^{\circ} \mathrm{W}, 45-50^{\circ} \mathrm{N}$, which is not evident in the satellite observation or the results of the model runs using FOAM and NCOM data.

On the northwest European continental shelf, volume fluxes through sections placed across strategic pathways appear mostly unaffected by the initial and boundary conditions used by the AMM. All model runs produced results consistent with observations. For sections that 
extended into deeper water off the continental shelf, the volume flux depended heavily on both the boundary and initial data sources. The affect was largest for the two sections in the southwest corner of the model domain and there is evidence that the run using climate data behaves differently from the runs using model output as boundary data. This might be a consequence of the lower temporal and spatial resolution of the climate data that misses some detail of the density field that is important for the correct modelling of the large-scale currents, or it might be that the climate temperature and salinity boundary conditions are inconsistent with the FOAM elevation and barotropic current data that are used to complete the boundary data set for the AMM-climate run. There appears to be no consistent difference between the models in the variabilities of the volume fluxes through the selected crosssections when considering the standard deviations of the daily-mean data (table 2).

By the balance between the pressure gradient and the Coriolis force, currents tend to be constrained to follow depth contours (Huthnance, 1995), on timescales longer than one day. This inhibits ocean-shelf exchanges in regions of steep bathymetry. Since POLCOMS is run without assimilation and is forced by the analysis of atmospheric and oceanic operational models, the AMM simulations are equivalent to 'nowcasts' in an operational system (rather than a forecast). The internal variability (and hence the predictability) of the circulation of these shelf seas is constrained strongly by the topography, shape of the shelf-sea basin and the location of fronts. Consequently, the shallow shelf region of the northeast Atlantic is largely unaffected by the choice of boundary condition in the AMM.

\section{Acknowledgements}

We thank Ruth Preller and Pam Posey of the Naval Research Laboratory, Stennis Space Center, USA for supplying the NCOM data and Martin Holt of the UK Met Office for supplying the FOAM data. AVHRR data from the NOAA/NASA Ocean Pathfinder satellite were downloaded from http://podaac.jpl.nasa.gov/sst and World Ocean Atlas 2005 climate data from http:/www.nodc.noaa.gov/OC5/WOA05/pr_woa05.html. This work was in part funded by the NERC EO centre of Excellence CASIX, and the EC FP5 Integrated Programme MERSEA (SIP3-CT-2003-502885).

\section{References}

Antonov, J. I., R. A. Locarnini, T. P. Boyer, A. V. Mishonov, and H. E. Garcia, 2006. World Ocean Atlas 2005, Volume 2: Salinity. S. Levitus, Ed. NOAA Atlas NESDIS 62, U.S. Government Printing Office, Washington, D.C., $182 \mathrm{pp}$.

Barron, C. N., A.B. Kara, P.J. Martin, R.C. Rhodes and L.F. Smedstad, 2006. Formulation, implementation and examination of vertical coordinate choices in the Global Navy Coastal Ocean Model (NCOM). Ocean Modelling, 11, 347-375.

Bell, M.J., R.M Forbes and A. Hines, 2000. Assessment of the FOAM global data assimilation system for real time operational ocean forecasting. Journal of Marine Systems, 25, 1-22.

Brown, J. and E. M. Gmitrowicz, 1995. Observations of the transverse structure and dynamics of the low frequency flow through the North Channel of the Irish Sea. Continental Shelf Research, 15, 1133-1156.

Bryan, K., 1969. A numerical method for the study of the circulation of the world ocean. J. Computational Physics, 4, 347-376.

Blumberg, A. F. and G. L. Mellor, 1987. A description of a three-dimensional coastal ocean circulation model. In Three-Dimensional Coastal Ocean Models, N. Heaps (Ed), 208 pp., American Geophysical Union.

Cox, M.D., 1984. A primitive equation 3-dimensional model of the ocean. GFDL Ocean Group Technical Report No. 1, Geophysical Fluid Dynamics Laboratory / NOAA, Princeton University, Princeton.

Fernand., L., G.D. Nolan, R. Raine, C.E. Chambers, S.R. Dye, M. White and J. Brown, 2006. The Irish coastal current: A seasonal jet-like circulation. Continental Shelf Research 26(15): 1775-1793.

Flather, R.A., 1981. Results from a model of the northeast Atlantic relating to the Norwegian Coastal Current. In The Norwegian Coastal Current, Proceedings from the Norwegian Coastal Current Symposium, Geilo, 912 September 1980, Vol. II: R. Saetre and M. Mork (Editors), pp. 427-458, University of Bergen, 1981.

Haidvogel, D.B., H.G. Arango, K. Hedstrom, A. Beckmann, P. Malanotte- Rizzoli, and A.F. Shchepetkin, 2000. Model evaluation experiments in the North Atlantic Basin: simulations in nonlinear terrain-following coordinates, Dyn. Atmos. Oceans, 32, 239-281. 
Haney, R. L., 1991. On the pressure gradient force over steep topography in sigma coordinate models. J. Phys. Oceanogr., 21, 610-619.

Hansen, B. and S. Østerhus, 2000. North Atlantic - Nordic Seas exchanges. Progress in Oceanography, 45, 109208.

Holt, J.T., J.I. Allen, R. Proctor, and F. Gilbert, 2005. Error quantification of a high resolution coupled hydrodynamic-ecosystem coastal-ocean model: part 1 model overview and assessment of the hydrodynamics. Journal of Marine Systems, 57, 167-188.

Holt, J.T. and I. D. James, 2001. An s-coordinate density evolving model of the north west European continental shelf. Part 1: Model description and density structure. J. Geophys. Res., 106(C7): 14015-14034.

Holt, J.T., and I.D. James, 2006. An assessment of the fine-scale eddies in a high resolution model of the shelf seas west of Great Britain. Ocean Modelling, 13, 271-291.

Holt, J.T., and R. Proctor, 2003. The role of advection in determining the temperature structure of the Irish Sea. Journal of Physical Oceanography, 33, 2288-2306.

Huthnance, J. M., 1995. Circulation, exchange and water masses at the ocean margin: the role of physical processes at the shelf edge, Progress in Oceanography, 35(4), 353-431.

Huthnance, J. M. and W.J. Gould, 1989. On the northeast Atlantic slope current. In Poleward flows along eastern ocean boundaries. Neshyba, S. J., C. N. K. Mooers, R. L. Smith and R. T. Barber, Eds. New York:Springer-Verlag, Coastal and Estuarine Studies, 34,76-81.

Knight, P.J. and M.J. Howarth, 1999. The flow through the north channel of the Irish Sea. Continental Shelf Research, 19, 693-716.

Locarnini, R. A., A. V. Mishonov, J. I. Antonov, T. P. Boyer, and H. E. Garcia, 2006. World Ocean Atlas 2005, Volume 1: Temperature. S. Levitus, Ed. NOAA Atlas NESDIS 61, U.S. Government Printing Office, Washington, D.C., $182 \mathrm{pp}$.

Maximenko, N.A. and P.P. Niiler, 2005. Hybrid decade-mean global sea level with mesoscale resolution. In N. Saxena (Ed.) Recent Advances in Marine Science and Technology, 2004, pp. 55-59. Honolulu: PACON International.

Mellor, G.L., T. Ezer and L.-Y. Oey, 1994. The pressure gradient conundrum of sigma coordinate ocean models. Journal of Atmospheric and Oceanic Technology, 11, 1126-1134.

Niiler, P. P., N. A. Maximenko, and J. C. McWilliams, 2003. Dynamically balanced absolute sea level of the global ocean derived from near-surface velocity observations, Geophys. Res. Lett., 30(22), 2164, doi:10.1029/2003GL018628.

Østerhus, S., W. R. Turrell, S. Jónsson, and B. Hansen, 2005. Measured volume, heat, and salt fluxes from the Atlantic to the Arctic Mediterranean, Geophys. Res. Lett., 32, L07603, doi:10.1029/2004GL022188.

Otto, L., J.T.F Zimmerman, G.K. Furnes, M. Mork, R. Saetre and G. Becker, 1990. Review of the physical oceanography of the North Sea. Neth. J. Sea Res., 26, 161-238.

Pingree, R. and B. Le Cann, 1989. Celtic and Armorican slope and shelf residual currents. Progress in Oceanography 23(4), 303-338.

Prandle, D., G. Ballard, D. Flatt, A.J. Harrison, S.E. Jones, P.J. Knight, S. Loch, J. McManus, R. Player and A. Tappin, 1996. Combining modelling and monitoring to determine fluxes of water, dissolved and particulate metals through the Dover Strait. Continental Shelf Research, 16(2), 237-257.

Proctor, R. and I.D. James, 1996. A fine resolution 3-D model of the southern North Sea. Journal of Marine Systems, 8, 285-294.

Song, Y. and D. Haidvogel, 1994. A semi-implicit ocean circulation model using a generalized topographyfollowing coordinate system. J. Comput. Phys., 115, 228-244.

Souza, A.J., J.H. Simpson, M. Harikrishnan and J. Malarkey, 2000. Flow structure and seasonality in the Hebridean slope current. Oceanlogica Acta, 24, S63-S76.

Young, E.F. and J.T. Holt, 2007. Prediction and analysis of long-term variability of temperature and salinity in the Irish Sea. J. Geophys. Res., 112 C01008, doi:10.1029/2005JC003386. 